\title{
OPTIMIZATION OF TREE LIGHTING IN PEACH GARDEN DUE TO SCHEMES OF PLANT LOCATION DENSITY
}

\author{
Sanjar Samadovich Khojiev \\ Independent Researcher, Senior Teacher of the Department of Soil Science, \\ Bukhara State University, Bukhara, Uzbekistan \\ Najdat Shavkatovich Enileev \\ Candidate of Agricultural Sciences, Docent of the Department Fruit Growing and Viticulture, Tashkent \\ State Agrarian University, Tashkent, Uzbekistan
}

Article DOI: https://doi.org/10.36713/epra3960

\begin{abstract}
In the article is given an experimental material devoted to exploration of the impact of peach tree placement schemes in the garden on the quality of lighting of the crown different parts in order to optimize plant placement in intensive gardens.

It was revealed significant differences in the inflow of photoactive solar radiation into the tree crown due to tree placement schemes, on the base of studies, carried out in 2015-2017 at Bukhara Agricultural Institute, branch of TashSAU with Lola variety of peach on a weak stock VVA-1. Most of all sunlight - 90 thousand lux comes to the intersections of the garden in spring-summer period. To the central part of crown from 72.0 to 104.7 thousand lux, between trees 69.6-93.9 thousand lux.

From studied tree placement schemes, the most solar photoactive radiation is supplied to plants with a thinned scheme from 86.5 to 104.7 thousand lux. This density of placement should be considered as determining when growing peach according to intensive technology.
\end{abstract}

KEYWORDS: Peach, garden, solar radiation, lux, scheme, crown, inter-row, lighting, growth, formation.

\section{INTRODUCTION}

Studies of fruit growers have found that the maximum possible use of solar radiation by plants, inflowing on the earth and fruit trees is on average 25 $28 \%$. For photosynthesis plants use $1-5 \%$ of solar energy [4].

High level of solar radiation usage in fruit garden of intensive type is provided due to rapid development of set aside food area and intensive growth of foliage canopy in compacted placement. Under these conditions, peach tree yield can reach maximum level in a short period [3].

The significant dependence of light flux absorption depending on the height of trees and the area of placement justifies the prerequisites for denser placement of trees in the garden [7].

Peach is a light-loving culture, which is related to its origin in such primary focal point of formation and domestication as China [2]. There can occur fast dying of the shaded overgrowing branches at thickening in trees.

The harvest of the trees having good lighting is formed beautiful coloring fruits and higher tastes in comparison with shaded ones. Therefore, peach trees need to be located on well-lit places, at the same time the crown needs to be formed more thinned for the best illumination of all plant [5].

\section{MATERIALS AND METHODS}

Scientific research on studying of influence of peach trees planting schemes in garden was conducted in 2015-2017 in Bukhara branch of the Tashkent state agrarian university.

As an object of the research Lola peach grade, zoned in Uzbekistan, has been used, which is grown up on weak vegetative propagated stock VSL-1 (Krymsky 5). 


\section{SJIF Impact Factor: 6.260| ISI I.F.Value:1.241| Journal DOI: 10.36713/epra2016 \\ ISSN: 2455-7838(Online) \\ EPRA International Journal of Research and Development (IJRD)}

Volume: 5 | Issue: 1 | January 2020

- Peer Reviewed Journal

Trees in garden have been planted according to schemes $6 \times 4$ meters (control), 6x3, 6x2 and 6x1.5 meters. In each option five trees were registrative. Frequency of experience quadruple. During vegetation on trees planting variations measurements of various structural parts of plants illumination were carried out by using the portable laboratory polarimeter $\mathrm{Yu}-17$ [6].

\section{RESULTS AND DISCUSSION}

Earlier conducted researches with peach culture in Uzbekistan have shown that to 5-6 age trees practically reach their maximum biological potential in morphological development of over ground and root systems. Therefore, for the maximum use of biological potential of plants, especially, at their cultivation according to the intensive thickened scheme of planting in garden it is very important to use exposition of plants placement correctly. In this case the correct conditions

\section{Table 1}

Influence of the placement scheme of Lola variety peach in the garden on the illumination degree of crown habitus (average on geographical position of crown parts), 2015-2017

\begin{tabular}{|c|c|c|c|c|c|c|}
\hline \multirow{3}{*}{$\begin{array}{l}\text { Scheme of trees } \\
\text { planting, } m \text {. }\end{array}$} & \multicolumn{6}{|c|}{ Lighting } \\
\hline & \multicolumn{2}{|c|}{ In the center of crown } & \multicolumn{2}{|c|}{ In a row } & \multicolumn{2}{|c|}{ In a row-spacing } \\
\hline & lux & $\%$ & lux & $\%$ & lux & $\%$ \\
\hline $6 \times 4$ & 72000 & 60,1 & 69600 & 58,3 & 108,000 & 90,0 \\
\hline $6 \times 3$ & 86160 & 71,8 & 77520 & 64,6 & 108100 & 90,0 \\
\hline $6 \times 2$ & 91680 & 76,4 & 86520 & 72,1 & 108150 & 90,0 \\
\hline $6 \times 1,5$ & 104760 & 87,3 & 93960 & 78,3 & 108210 & 90,0 \\
\hline $\begin{array}{l}\text { Average on } \\
\text { versions }\end{array}$ & 88600 & 73,9 & 81800 & 68,3 & 108000 & 90,0 \\
\hline $\mathrm{LSD}_{05}$ & 3120 & - & 6340 & - & 0,12 & - \\
\hline
\end{tabular}

Note: calculations are given from full PAR in the open space of the experimental plot - 120 thousand lux.

From 69.6 to 93.96 thousand lux of solar energy come to rows between peach trees. The greatest quantity of such energy arrives to trees in a row in the following planting schemes $6.0 \times 1.5$ and $6.0 \times 2.0$ meters -93.6 and 86.6 thousand lux or 78.2 and $60.0 \%$ of the general PAR (solar radiant energy).

Into row-spacings of peach garden planted by Lola grade, grown up on weak vegetative propagated stock VVA-1 gets approximately identical amount of light irrespective of the scheme of trees planting in garden. We connect this quantitative index of abiotic ecological factor with the fact that the space in row-spacings in six age still isn't completely mastered by crown of peach trees.

By examination of trees illumination level at free individual growth, it is revealed that on the geographical relation to the sides of the world illumination level in

of plants development as in year cycle of development, and ontogenesis will be provided [1].

The conducted scientific research has shown that irrespective of peach placement density in garden the greatest number of solar energy (PAR) comes to rowspacings -108 thousand lux from the general maximum summer 120 thousand lux, that makes $98 \%$. In the center of crown illumination level in connection with schemes of trees planting can reach 88.6 thousand lux, row-spacing - to 81.8 thousand lux or respectively 73.8 and $68.1 \%$ of the general radiant energy (PAR).

By versions of trees planting schemes and their density on area unit of garden inflow of sun light into trees crown increases from sparser to thickened schemes from 72.0 to 104.7 thousand lux, i.e. for 32.7 thousand lux or $38.8 \%$ more (Table 1 ). Lighting 
Table 2

Illumination level of crown various parts of Lola grade peach, grown up on stock VVA-1 in connection with their geographic location, 2015-2017

\begin{tabular}{|c|c|c|c|c|c|c|}
\hline \multirow{2}{*}{$\begin{array}{c}\text { Exposition of } \\
\text { trees }\end{array}$} & \multicolumn{6}{|c|}{ Lighting of crown parts } \\
\cline { 2 - 6 } & \multicolumn{2}{|c|}{ In the center of crown } & \multicolumn{2}{c|}{ In a row } & \multicolumn{2}{c|}{ In a row-spacing } \\
\cline { 2 - 6 } & lux & $\mathbf{\%}$ & lux & $\mathbf{\%}$ & lux & $\mathbf{\%}$ \\
\hline Eastern & 88100 & 73,3 & 87320 & 72,7 & 110020 & 91,6 \\
\hline Southern & 97110 & 80,8 & 89920 & 74,9 & 120090 & 100,0 \\
\hline Western & 91200 & 75,8 & 89230 & 74,2 & 115170 & 95,8 \\
\hline Northern & 75050 & 62,5 & 73900 & 61,5 & 85550 & 70,8 \\
\hline $\begin{array}{c}\text { Average on crown } \\
\text { zones }\end{array}$ & 87865 & 73,1 & 85092 & 70,8 & 107707 & 89,5 \\
\hline LSD $_{05}$ & 5120 & & 2100 & & 10020 & \\
\hline
\end{tabular}

The inter-row space of trees in the garden is illuminated much more- up to 120090 lux. The obtained experimental data on the features of trees crown illumination in the garden should be used in optimizing the schemes of peach placement in the garden, grown according to intensive technology.

\section{CONCLUSION}

1. When growing peach in the conditions of Bukhara region in the crown of a separate tree in spring - summer period, on average comes 87865 lux of sunlight, from them to the Southern part - 97110, to the Western - 91200, to the Eastern - 88100 and to the Northern - 75050 lux, which is quite sufficient for accumulation of plastic substances by plants used by them for laying generative shoots in the above-ground part.

2. The level of solar energy entering the crown of peach trees, grown on a weak vegetative propagated stock VVA-1, under various placement schemes and planting density of trees shows that more sunlight enters the crown in the following planting schemes $6.0 \times 2.0$ meters and $6.0 \times 1.5$ meters. - from 91690 to 104.760 thousand lux. The level of illumination decreases to $29.5 \%$ in sparser planting, which is due to the large volume of crown trees.

3. In order to maximize the biological potential of Lola grade peach, when growing according to intensive technology, plants should be placed in the garden according to the scheme of $6.0 \times 2.0$ meters with density of standing on a unit of area up to 833 pieces, at which the level solar photoactive radiation reaches a maximum level - 91680 lux.

\section{REFERENCES}

1. Alekseeva O.N. (1966). Peach cultivation in intensive gardens of the South Ukraine. Farming, № 2. pp. 5-6.

2. Golovanov I.S. (1966). Density of plantations in the garden. Journal of Science of Kazakhstan. Almaty, №1. pp. 75-83.

3. Rasulov A.V. (1999). Agroecological foundations for increasing productivity of fruit crops in the conditions of the North Caucasus foothills. Moscow, $43 p$.

4. Senin V.I., Kovaleva A.F. (1984). New in intensive horticulture. - Dnepropetrovsk: Prolin, 232 p.

5. Shaitan I.M., Chuprin L.M. (1989). Biological features of peach, apricot and cherry-plum growing. - Kiev: Naukova dumka, 256 p.

6. Yenileev N.S. (2019). Method of phenological observations and biometric accounting during scientific research with fruit and berry plants. Tashkent, TashSAU, 72 p.

7. Zulunsky M.I., Ponomarenko V. V. (1992). Area of light nutrition of plants and layout of fruit cultures plantations. Report of the Russ. Acad. Agricul. Sciences, №2. pp.16-18. 